\title{
A Randomized Open Label Parallel Group Clinical Study to Evaluate the Efficacy and Safety of Clevira in Fever of Viral Origin
}

\author{
Ramesh Kannan S. ${ }^{1}$, Sivraman V. ${ }^{1}$, Vanitha R Muralikumar ${ }^{2}$, Sakthibalan M. ${ }^{* 3}$, Jayashree S. ${ }^{3}$, \\ Vanangamudi Ss ${ }^{4}$, Nagarajan $\mathrm{Km}^{4}$, Arther Paul $\mathrm{C}^{4}{ }^{4}$ \\ ${ }^{1}$ Principal Investigators, Department of Pharmacology, Madras Medical College, Chennai, India \\ ${ }^{2}$ Co-Investigators, Director, Research, Sri Sairam Ayurveda Medical College, Chennai \\ ${ }^{3}$ Co-Investigators, KI3 (CRO), Chennai, India \\ ${ }^{4}$ Co- Investigators, Apex Laboratories Pvt. Ltd., Chennai, India
}

Corresponding Author: Dr. M. Sakthibalan; kai3.mrg@gmail.com

Received 12 September 2019;

Accepted 29 September 2019;

Published 03 October 2019

\begin{abstract}
Objective: To evaluate the efficacy and safety of Clevira, an ayurvedic formulation in fever of viral origin. Methods: This was a prospective, randomised, multicentre, open label, parallel group interventional clinical end point study. Patients attending general outpatient department, were screened for viral fever including Dengue by using the haematological, Biochemical and microbiological anti body assay for Dengue and NS1 (Non-structural protein) antigen testing. Forty eight patients who satisfied the selection criteria were enrolled in the study. Participants were randomized into 4 groups with 12 patients in each group. Patients were given standard treatment. In addition, Tab. Clevira of Apex laboratories Pvt. Ltd., was administered to test groups. $\underline{\text { Results: }}$ There is highly significant improvement $(\mathrm{P}<0.001)$ in the subjects Temperature, fever score, arthralgia score, Myalgia score, Headache and loss of appetite, suggesting a good Analgesic and anti pyretic activity of Clevira. There is a significant improvement in platelet count in the Clevira treated group $(\mathrm{P}<0.01)$ when compared to the control group, proving its efficacy in treating thrombocytopenia. The improvement $(\mathrm{P}<0.01)$ in the WBC count in the Clevira treated group depicts the anti viral property of Clevira. The overall quality of life was better in Clevira treated group compared to the control group. There were no serious adverse events reported. Conclusion: Clevira is safe and efficacious in reversing thrombocytopenia and thus normalizing the platelet counts and relieving the clinical signs and symptoms (fever, myalgia, arthralgia, headache) of Viral fever associated with thrombocytopenia and other cases of viral fever without thrombocytopenia. Clevira is having good anti-viral, antipyretic, analgesic and immunomodulatory property. Hence, Clevira should be used as an add on drug in patients with viral fever with or without thrombocytopenia for a rapid recovery without any adverse effects.
\end{abstract}

Keywords: Viral fever, Dengue, Clevira, Anti viral, Anti pyretic, analgesic.

\section{Introduction}

Fever is a clinical feature that manifests due to an infection. The infection may be due to a virus, Bacteria or other microorganisms. Viral fever is a condition characterized by a temperature above 38.0 to 38.4 (100.4 F to $101 \mathrm{~F}$ ) associated with symptoms like sudden onset of fever, severe headache especially behind the eyes, severe joint and muscle pain, nausea and vomiting \& sometime accompanied by body rash persisting for four to seven days after infection. Viral infections include Herpes, Chikungunya, Dengue, Influenza, etc. ${ }^{[1,2]}$

Dengue fever was considered a sporadic disease known to cause epidemics at stretched intervals. Currently, dengue ranks as one of the most important mosquito borne viral disease. The incidence of dengue has increased 30-fold. At present, dengue is endemic in 112 countries in the world. ${ }^{[3,4]}$ It is estimated that around 3.9 billion people, living in urban areas of tropical and subtropical regions of 128 countries,, are at a huge risk of acquiring dengue viral infections. ${ }^{[5]}$ Current estimates propose that 390 million dengue infections occur per year (95\% credible interval 284-528 million), of which 96 million are manifesting clinically with any severity of disease. The number of cases reported increased from 2.2 million in 2010 to over 3.34 million in 2016. ${ }^{[6]}$ Patients who are suffering from Dengue haemorrhagic fever are usually children with less than 15 years of age. ${ }^{[4]}$

Dengue, known as break-bone fever, is an infectious tropical disease caused by the dengue virus. Symptoms include high grade fever, headache, muscle and joint pains, and accompanied by a characteristic skin rash. In few it gets complicated into the lifethreatening dengue hemorrhagic fever, resulting in bleeding, low 
levels of blood platelets and plasma leakage. ${ }^{[7,8]}$ Currently there is no approved vaccine or drug against dengue viral infection. Various researches are ongoing on to find an effective vaccine. ${ }^{[9]}$

There are no specific therapeutic options for the clinical management of many viral infections besides supportive care. Henceforth there exists an urgent need for development of an alternative solutions for dengue. Products obtained from various plant species have been reported with anti-dengue and other anti viral properties. The various plant species are that of Carica papaya, Andrographis paniculata, Tinospora cordifolia, Piper nigrum, Melia azedarach etc. ${ }^{[10-17]}$

In a country like India we have a rich source of herbs having anti viral and antipyretic activity. In recent days we have started using many siddha formulations for various illnesses. Clevira is one among them which is a polyherbal formulation consisting of many ingredients. Composition of one CLEVIRA tablet includes extracts namely: Erandakarkati (Carica papaya)-Lf. - 100mg, Mahanimba (Melia azedarach)-Lf. - 100mg, Kalmegh (Andrographis paniculata)-Herb - 100mg, Usira (Vettivera zizanoides)-Rt.- 35mg, Patola (Tricosanthus dioica)-Wh.Pl.$35 \mathrm{mg}$, Musta (Cyperus rotundus)-Rz. - 35mg, Sunthi (Zingiber officinale)- Rz. - 35mg, Maricha (Piper nigrum)-Fr. - 35mg, Grismachatraka (Mollugo cerviana)-Wh.Pl.- 35mg, Guduchi (Tinospora cordifolia)-St. - 10mg. Clevira is a Proprietary Ayurvedic Medicine. The individual herbal drugs used are known to have variety of medicinal values against fever of viral origin and proven to have effective antipyretic, analgesic, anti-viral and immunity boosting properties.

Hence, the present study has been planned with an objective to evaluate the efficacy and safety of Clevira tablets in fever of viral origin.

\section{Aim \& Objectives}

1. To study the efficacy of Clevira in fever due to viral origin.

2. To assess the safety of Clevira by monitoring the occurrence of any adverse events and assess the quality of life using a pre-and post-feedback questionnaire.

\section{Methodology}

This was a prospective, randomised, multicentre, open label, parallel group interventional clinical end point study (Phase IIa). The study was conducted during the period of January to June 2019. The study was conducted by investigator from Madras Medical College, Chennai and other co investigators, at two centres in India namely Sri Sairam Ayurveda Medical College, Chennai and PM Medical Centre, Walajapet, Tamil Nadu, according to Good Clinical Practice. The study was initiated after obtaining proper ethical committee approvals in ki3 ethics committee. The study was registered in Clinical trial registry of India (No:
CTRI/2019/02/017565) and DCGI- Drug Control General of India (AYUSH) was notified(Notification No: 4022). Informed written consent was obtained from the patients attending General Medicine outpatient department. Then they underwent general and systemic examination followed by laboratory tests for haematology, blood biochemistry, blood microbiology, urine analysis, electrocardiogram and chest X-ray for initial evaluation and were screened for anti body assay for Dengue and Dengue NS1 antigen testing.

- Patients recruited in the study belonged to;

1. Either sex- between the age of $18-75$ years, with an oral temperature of more than $38.0^{\circ} \mathrm{C}\left(100.4^{\circ} \mathrm{F}\right)$. with or without associated rash, body pain and joint pain, severe headache especially behind the eyes, nausea and vomiting.

2. With Viral fever accompanied by thrombocytopenia (in group 1 and 2), with a platelet count between 80,000 /micro litre to100,000/micro litre, along with stable vitals like pulse and blood pressure.

3. Female patients who tested negative for pregnancy (up to two weeks prior to the study).

- Patients who were excluded from the study includes;

1. Patients with Dengue hemorrhagic fever grade III and IV

2. Patients with platelet count less than $80,000 /$ micro litre.

3. Pregnant or lactating women

4. Patients who have received blood or blood products transfusion during the current illness

5. Patients with thrombocytopenia Purpura (ITP), Leukemia, Hemophilia

6. Patients with serum ALT level 3 times higher than the upper limit of the normal range (>165 U/L) and Impaired renal function with serum creatinine $>1.5 \mathrm{mg} / \mathrm{dl}$ (males) and $>1.4 \mathrm{mg} / \mathrm{dl}$ (females).

7. Patients who were hypersensitive to any of the components of the formulation,

Totally 89 patients were screened for fulfilment of the selection criteria and 48 patients were then enrolled in the study. Forty eight patients were then randomized (block randomization) into 4 groups with 12 patients in each group.

Group 1: Patients diagnosed as viral fever with thrombocytopenia received treatment as per the physician advice. In addition tablet Clevira was given twice daily for 7 days.

Group 2: Patients diagnosed as viral fever with thrombocytopenia received treatment as per the physician advice.

Group 3: Patients diagnosed as viral fever other than fever with thrombocytopenia received treatment as per the physician advice. In addition tablet Clevira was given twice daily for 7 days.

Group 4: Patients diagnosed as viral fever other than fever with thrombocytopenia received treatment as per the physician advice.

\section{Participant flow diagram:}

Consort diagram: interventional clinical end point study

Assessed for eligibility $(n=89)$

\begin{tabular}{|l|l|}
\hline $\begin{array}{l}\text { Excluded }(\mathrm{n}=41) \\
\text { Not meeting inclusion \& exclusion criteria } \\
(\mathrm{n}=36) \\
\text { Refused to participate }(\mathrm{n}=5)\end{array}$ \\
\hline
\end{tabular}




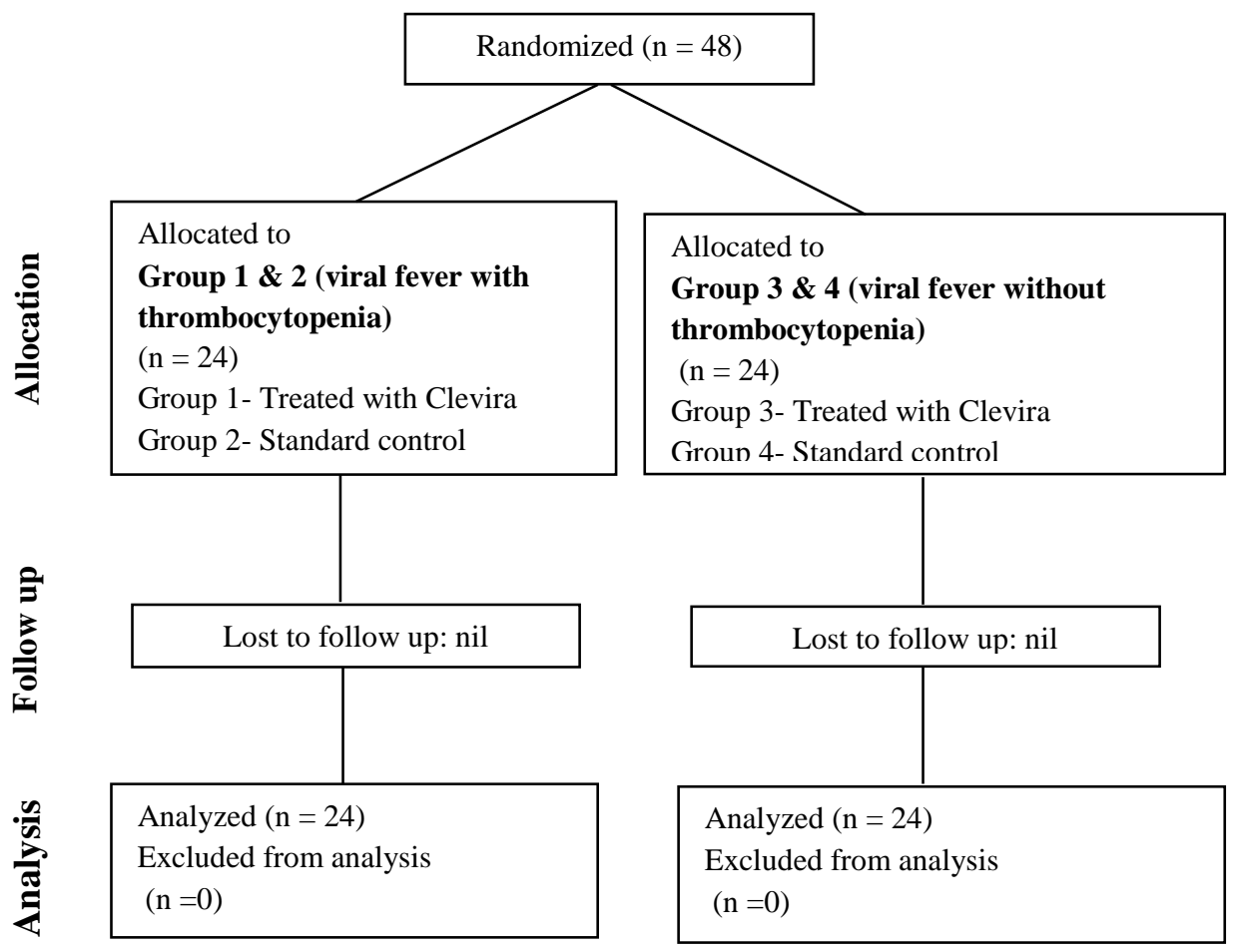

Patients were given standard treatment of care in all the groups. In addition, one tablet of Clevira (manufactured by Apex laboratories Pvt. Ltd.,) was administered twice daily for one week, for the patients of test group 1 and 3. The patients were monitored daily and parameters namely platelet count, haematocrit, prothrombin time, bleeding time, clotting time were assessed from baseline \& on each day from day 1 to day 3 and on day $5 \& 7$ (For 24 subjects who suffer from viral fever with thrombocytopenia of group 1 \& 2). Clinical parameters namely temperature, fever score, arthralgia, myalgia, headache and loss of appetite were assessed from baseline and on day 1 to day 3 and on day $5 \& 7$. (For all 48 subjects). Scoring of fever was done on a scale of $0-3$ where $0 \leq 99^{\circ} \mathrm{F}, 1 \geq$ $99-100^{\circ} \mathrm{F}, 2 \geq 101-102^{\circ} \mathrm{F}, 3 \geq 102^{\circ} \mathrm{F}$. (For all 48 subjects). Similarly scoring for arthralgia, myalgia, headache and loss of appetite was done. The secondary outcome measures was to look for any adverse events during the study period and assess the quality of life using a pre-and post-feedback. (For all 48 subjects).

The reports were compiled. Continuous data was reported using the descriptive statistics using Mean and standard deviation. Two way ANOVA followed by Bonferroni's test was applied for statistical analysis of significance. $\mathrm{P}$ value of $<0.05$ was considered as statistically significant. All the statistical analysis was performed using SPSS 23.0 software.

\section{Results}

The trial population consisted of 48 subjects, of which 24 adult subjects were diagnosed with viral fever associated with thrombocytopenia and 24 subjects were diagnosed with viral fever without thrombocytopenia. Before the study initiation, the subjects were screened and selected according to their inclusion and exclusion criteria. There were nine confirmed cases of Dengue NS1 positive, out of which five were in the Clevira group and four were in the control group.

All 48 subjects completed the study. There were no serious adverse events recorded during the study duration.

Table 1 gives the analysis of demographic data.

Table 2 gives the assessment of clinical parameters assessed on Screening, end of Day 1, Day 2, Day 3, Day 5 and Day 7 and compared with the Standard treatment group.

Table 3 shows the analysis of Study specific efficacy parameters assessed on Screening, at the end of Day 1, Day 2, Day 3, Day 5 and Day 7 and compared with the Standard treatment Group.

Table 4 shows the analysis for safety parameters based on the hematological and biochemical investigations assessed at Screening/Baseline and End of the study and compared with the Standard treatment Group.

Table 5 shows the assessment of Quality of Life at Screening and at the end of Day 7 (End of the study).

Table 6 shows the adverse events observed during the study period. Table 7 shows the overall assessment at the end of the study compared to Screening and to that of the standard treatment group.

Table 1: Demographic Data

\begin{tabular}{|l|l|l|l|l|}
\hline $\begin{array}{l}\text { Demographic } \\
\text { details }\end{array}$ & $\begin{array}{l}\text { Group 1 (Clevira)- Viral } \\
\text { fever with } \\
\text { thrombocytopenia }\end{array}$ & $\begin{array}{l}\text { Group 2 (Control) - Viral } \\
\text { fever with } \\
\text { thrombocytopenia }\end{array}$ & $\begin{array}{l}\text { Group 3 (Clevira)- Viral } \\
\text { fever without } \\
\text { thrombocytopenia }\end{array}$ & $\begin{array}{l}\text { Group 4 (Control) - } \\
\text { Viral fever without } \\
\text { thrombocytopenia }\end{array}$ \\
\hline No. of subjects & 12 & 12 & 12 & 12 \\
\hline Gender(M:F) & $9: 3$ & $7: 5$ & $8: 4$ & $7: 5$ \\
\hline Mean Age & $37.08 \pm 4.1$ & $30.58 \pm 5.3$ & $32.0 \pm 3.2$ & $30.33 \pm 5.1$ \\
\hline Mean BMI & $24.5 \pm 2.3$ & $25.1 \pm 4.7$ & $26.4 \pm 5.6$ & $26.7 \pm 3.9$ \\
\hline
\end{tabular}

(Two-way ANOVA followed by Bonferroni post-test. $P$ value (>0.05) was not significant for baseline parameters) There is no significance difference among the subjects in all the four groups. They were comparable in all aspects. 
Table 2: Analysis of patient's symptoms

\begin{tabular}{|c|c|c|c|c|c|}
\hline $\begin{array}{l}\text { Clinical } \\
\text { symptoms }\end{array}$ & $\begin{array}{l}\text { Scheduled } \\
\text { visits }\end{array}$ & $\begin{array}{l}\text { Group } 1 \text { (Clevira)- } \\
\text { Viral fever with } \\
\text { thrombocytopenia }\end{array}$ & $\begin{array}{l}\text { Group 2(Control)- } \\
\text { Viral fever with } \\
\text { thrombocytopenia }\end{array}$ & $\begin{array}{l}\text { Group } 3 \text { (Clevira)- } \\
\text { Viral fever without } \\
\text { thrombocytopenia }\end{array}$ & $\begin{array}{l}\text { Group } 4 \text { (Control)- } \\
\text { Viral fever without } \\
\text { thrombocytopenia }\end{array}$ \\
\hline \multirow[t]{6}{*}{ Temperature* } & Screening & $101.8 \pm 1.12$ & $101.2 \pm 1.12$ & $102.3 \pm 1.12$ & $101.9 \pm 0.71$ \\
\hline & Day 1 & $101.0 \pm 1.11$ & $101.2 \pm 0.61$ & $100.7 \pm 1.20$ & $101.2 \pm 0.55$ \\
\hline & Day 2 & $100.5 \pm 1.07$ & $100.5 \pm 1.07$ & $100.3 \pm 0.66$ & $101.3 \pm 0.66$ \\
\hline & Day 3 & $99.4 \pm 0.42$ & $100.2 \pm 0.35$ & $99.9 \pm 0.78$ & $100.1 \pm 1.02$ \\
\hline & Day 5 & $98.5 \pm 0.50$ & $99.1 \pm 0.25$ & $98.3 \pm 0.43$ & $98.9 \pm 0.25$ \\
\hline & Day 7 & $98.5 \pm 0.47$ & $99.4 \pm 0.53$ & $98.4 \pm 0.61$ & $98.5 \pm 0.80$ \\
\hline \multirow[t]{6}{*}{ Fever score* } & Screening & $3 \pm 0.40$ & $3 \pm 0.50$ & $3 \pm 0.25$ & $3 \pm 0.62$ \\
\hline & Day 1 & $2.89 \pm 0.54$ & $2.97 \pm 0.45$ & $2.85 \pm 0.48$ & $2.59 \pm 0.12$ \\
\hline & Day 2 & $2.13 \pm 0.20$ & $2.80 \pm 0.64$ & $2.22 \pm 0.85$ & $2.23 \pm 0.32$ \\
\hline & Day 3 & $1.56 \pm 0.26$ & $2.04 \pm 0.50$ & $1.50 \pm 0.21$ & $1.94 \pm 0.45$ \\
\hline & Day 5 & $0.67 \pm 0.10$ & $1.75 \pm 0.38$ & $0.45 \pm 0.20$ & $1.09 \pm 0.25$ \\
\hline & Day 7 & $0.24 \pm 0.12$ & $0.68 \pm 0.33$ & $0.14 \pm 0.45$ & $0.45 \pm 0.22$ \\
\hline \multirow{6}{*}{$\begin{array}{l}\text { Arthralgia } \\
\text { score* }\end{array}$} & Screening & $0.45 \pm 0.95$ & $0.52 \pm 0.66$ & $0.41 \pm 0.32$ & $0.55 \pm 0.81$ \\
\hline & Day 1 & $0.41 \pm 0.41$ & $0.49 \pm 0.46$ & $0.38 \pm 0.22$ & $0.50 \pm 0.31$ \\
\hline & Day 2 & $0.38 \pm 0.20$ & $0.45 \pm 0.11$ & $0.35 \pm 0.11$ & $0.45 \pm 0.30$ \\
\hline & Day 3 & $0.25 \pm 0.22$ & $0.30 \pm 0.28$ & $0.22 \pm 0.32$ & $0.35 \pm 0.41$ \\
\hline & Day 5 & $0.14 \pm 0.12$ & $0.19 \pm 0.13$ & $0.18 \pm 0.16$ & $0.22 \pm 0.24$ \\
\hline & Day 7 & $0.05 \pm 0.05$ & $0.05 \pm 0.12$ & $0.15 \pm 0.08$ & $0.16 \pm 0.13$ \\
\hline \multirow{6}{*}{ Myalgia score* } & Screening & $2.45 \pm 1.34$ & $2.33 \pm 1.51$ & $2.16 \pm 1.45$ & $2.20 \pm 0.95$ \\
\hline & Day 1 & $2.29 \pm 1.11$ & $2.25 \pm 1.07$ & $2.0 \pm 1.54$ & $2.05 \pm 1.01$ \\
\hline & Day 2 & $1.04 \pm 1.01$ & $1.65 \pm 0.94$ & $1.74 \pm 1.04$ & $1.65 \pm 1.33$ \\
\hline & Day 3 & $0.68 \pm 0.54$ & $1.05 \pm 1.01$ & $0.79 \pm 0.61$ & $0.85 \pm 0.35$ \\
\hline & Day 5 & $0.35 \pm 0.09$ & $0.51 \pm 0.38$ & $0.42 \pm 0.23$ & $0.55 \pm 0.27$ \\
\hline & Day 7 & $0.18 \pm 0.1$ & $0.25 \pm 0.18$ & $0.32 \pm 0.17$ & $0.37 \pm 0.21$ \\
\hline \multirow{6}{*}{$\begin{array}{l}\text { Headache } \\
\text { score* }\end{array}$} & Screening & $2.0 \pm 1.2$ & $1.98 \pm 0.98$ & $1.87 \pm 1.30$ & $2.0 \pm 0.79$ \\
\hline & Day 1 & $1.56 \pm 1.03$ & $1.95 \pm 1.55$ & $1.47 \pm 1.20$ & $1.81 \pm 0.88$ \\
\hline & Day 2 & $1.22 \pm 0.99$ & $1.56 \pm 1.41$ & $1.22 \pm 1.04$ & $1.36 \pm 1.05$ \\
\hline & Day 3 & $0.98 \pm 0.79$ & $1.10 \pm 0.91$ & $0.76 \pm 0.39$ & $0.98 \pm 0.55$ \\
\hline & Day 5 & $0.62 \pm 0.33$ & $0.78 \pm 0.46$ & $0.46 \pm 0.11$ & $0.47 \pm 0.30$ \\
\hline & Day 7 & $0.21 \pm 0.17$ & $0.32 \pm 0.31$ & $0.19 \pm 0.24$ & $0.15 \pm 0.27$ \\
\hline \multirow{6}{*}{$\begin{array}{l}\text { Loss of } \\
\text { appetite score* }\end{array}$} & Screening & $0.49 \pm 0.11$ & $0.45 \pm 0.54$ & $0.39 \pm 0.30$ & $0.42 \pm 0.28$ \\
\hline & Day 1 & $0.45 \pm 0.21$ & $0.40 \pm 0.21$ & $0.34 \pm 0.10$ & $0.36 \pm 0.12$ \\
\hline & Day 2 & $0.38 \pm 0.15$ & $0.37 \pm 0.15$ & $0.23 \pm 0.13$ & $0.29 \pm 0.11$ \\
\hline & Day 3 & $0.24 \pm 0.09$ & $0.20 \pm 0.09$ & $0.19 \pm 0.07$ & $0.20 \pm 0.10$ \\
\hline & Day 5 & $0.15 \pm 0.07$ & $0.11 \pm 0.07$ & $0.10 \pm 0.04$ & $0.14 \pm 0.09$ \\
\hline & Day 7 & $0.06 \pm 0.06$ & $0.05 \pm 0.12$ & $0.1 \pm 0.07$ & $0.1 \pm 0.05$ \\
\hline
\end{tabular}

(Table analysis: Two-way ANOVA followed by Bonferroni post-test. $* P<0.001$ - significant)

\section{Fig 1:Reduction in Body Temperature}

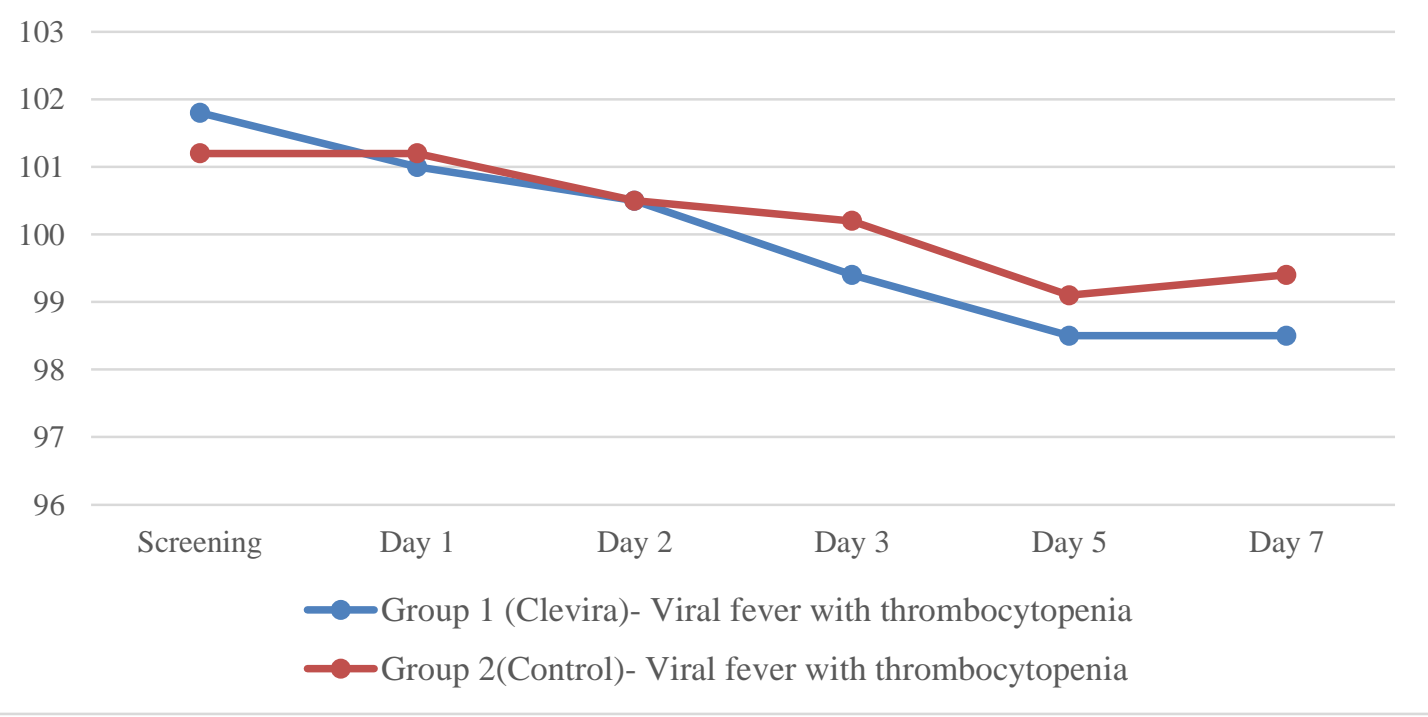


Fig 2:Reduction in Body Temperatue

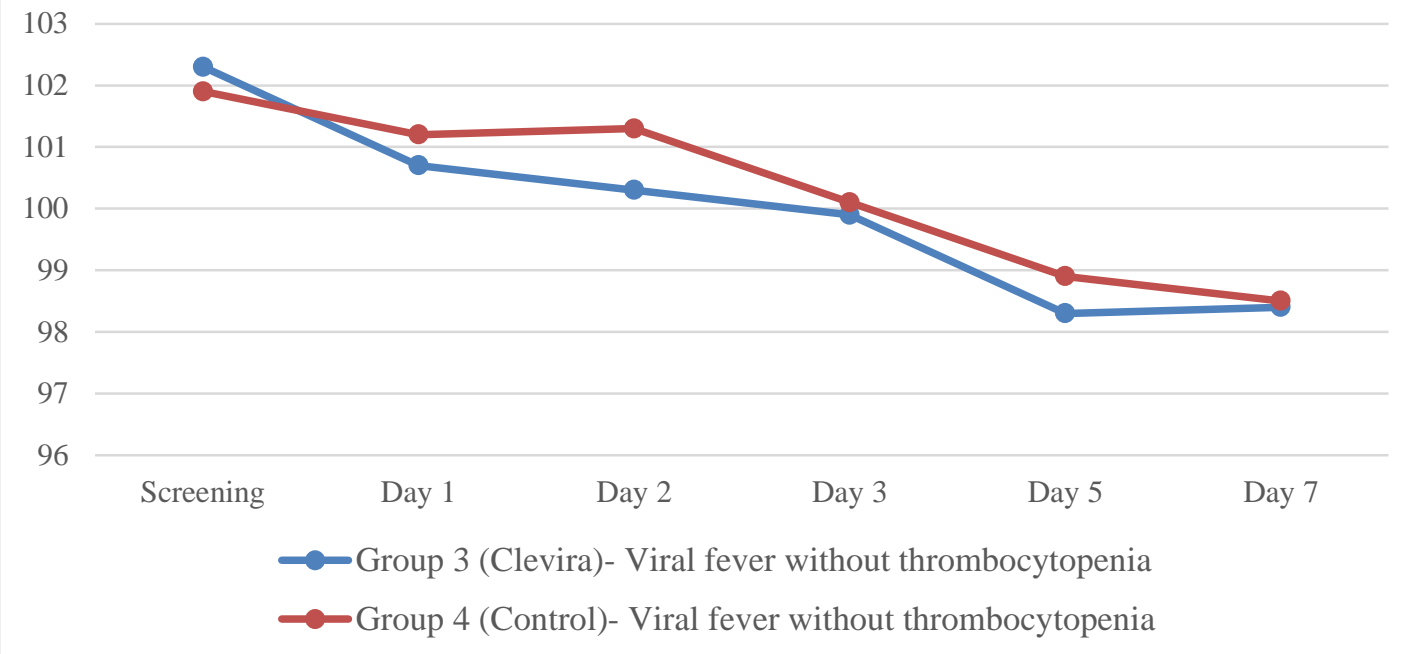

Fig 3:Improvement in Arthralgia score

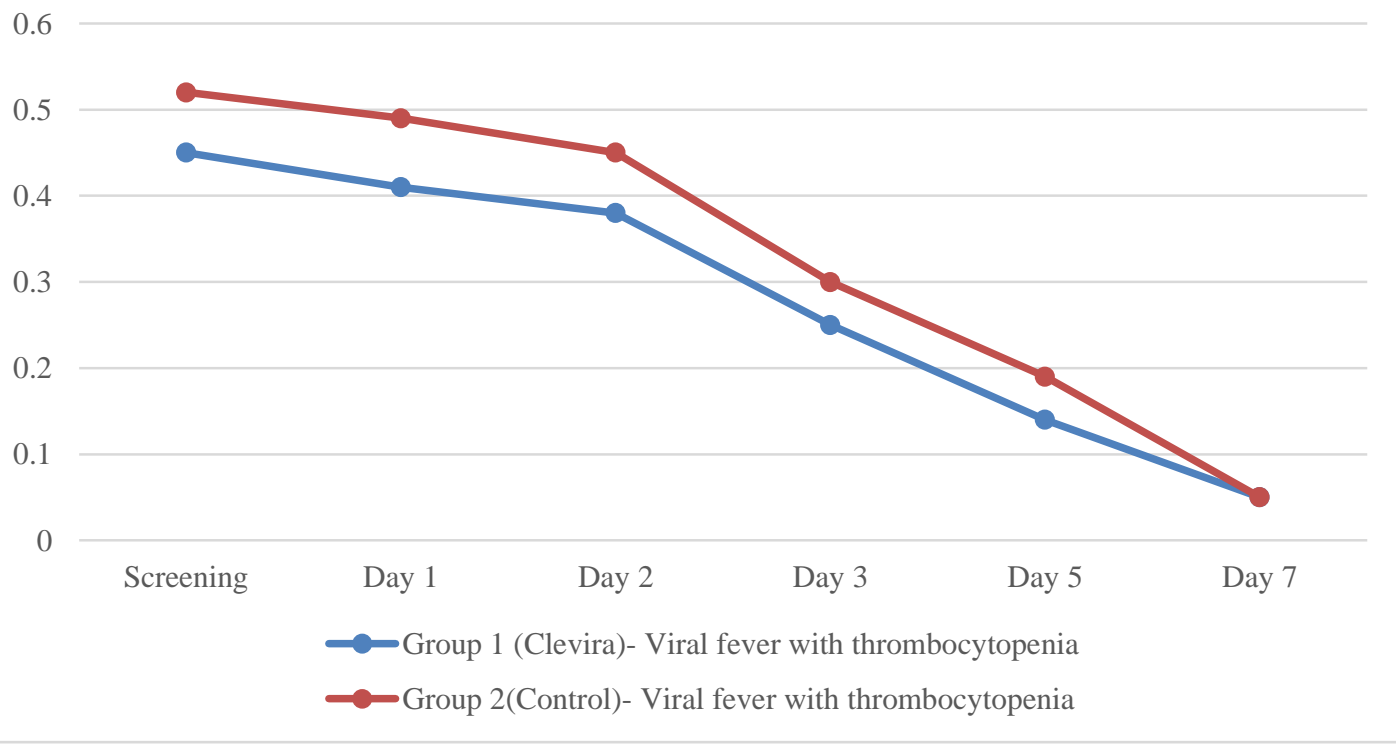

Fig 4: Improvement in Arthralgia score

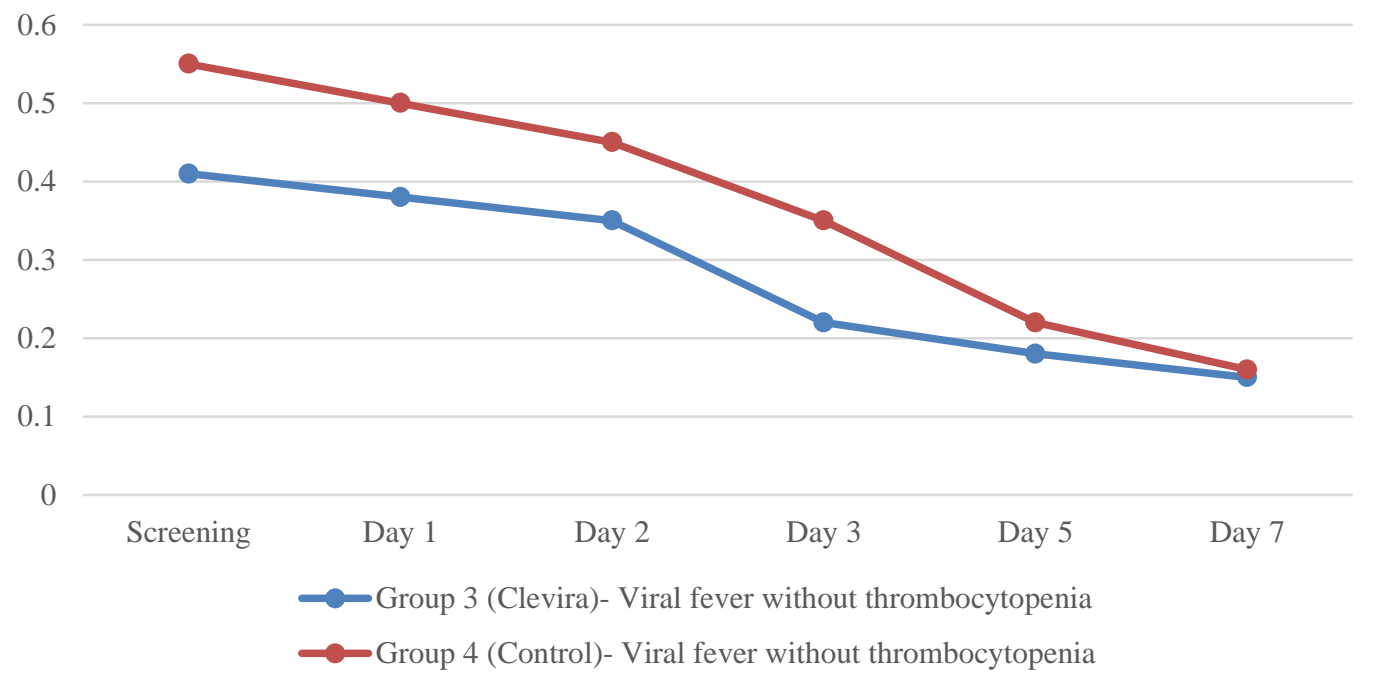




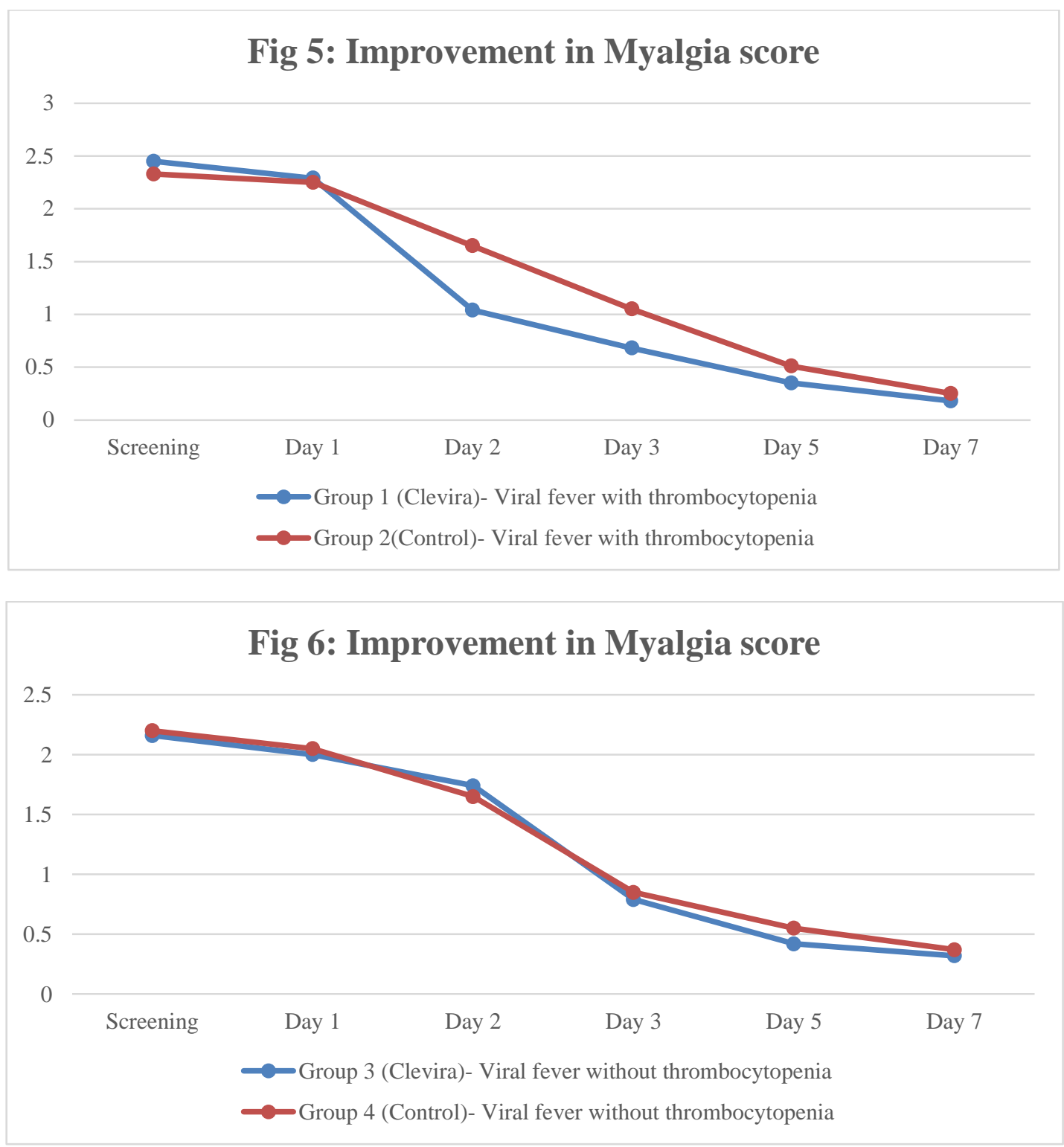

There is highly significant difference on comparing with the scores on screening/baseline with Day 7 ( $\mathrm{P}<0.001) *$ in all the four groups. There is improvement in the subjects Temperature, fever score, arthralgia score, Myalgia score, Headache and loss of appetite.(Table 2)

As depicted in Figure $1 \& 2$, the normalisation of body temperature was evident on Day 5 onwards in Clevira treated group (P<0.001)*, compared to the control group were it was improving after day 6 and 7. Thus, Clevira is having a good anti Pyretic activity.

From Figure 3,4,5 \& 6, it is evident that Clevira is having a significant improvement $(\mathrm{P}<0.001) *$ in the Arthralgia and Myalgia score on day 3,4 $\& 5$, compared to the control group were it was improving on day 5, 6 and 7, suggesting a good Analgesic and anti pyretic activity of Clevira.

Thus a significant improvement (quantitatively) in the Temperature, fever score, Myalgia score, arthralgia score and Headache score (P<0.001)* was noted in the Clevira treated group, when compared with the control group. The loss of appetite was comparable equally in both the groups.

Table 3: Assessment of specific Efficacy Lab parameters

\begin{tabular}{|l|l|l|l|}
\hline $\begin{array}{l}\text { Specific Efficacy Lab } \\
\text { parameters }\end{array}$ & $\begin{array}{l}\text { Scheduled } \\
\text { visits }\end{array}$ & $\begin{array}{l}\text { Group 1 (Clevira) - Viral fever with } \\
\text { thrombocytopenia }\end{array}$ & $\begin{array}{l}\text { Group 2 (Control) - Viral fever with } \\
\text { thrombocytopenia }\end{array}$ \\
\hline Platelet cells/mm3 & Screening & $84879.5 \pm 15654.2$ & $93648.57 \pm 8547.3$ \\
\cline { 2 - 4 } & Day 1 & $85333.3 \pm 14756.3$ & $92545.45 \pm 7188.3$ \\
\cline { 2 - 4 } & Day 2 & $79111.1 \pm 8738.4$ & $83454.55 \pm 11561.6$ \\
\cline { 2 - 4 } & Day 3 & $110000.0 \pm 31831.5$ & $84636.36 \pm 37092.5$ \\
\cline { 2 - 4 } & Day 4 & $188944.4 \pm 36534.6$ & $134272.7 \pm 82916.9$ \\
\cline { 2 - 4 } & Day 5 & $198666.7 \pm 21650.6$ & $150350.0 \pm 90319.8$ \\
\cline { 2 - 4 } & Day 7 & $258944.4 \pm 14945.4$ & $44.36 \pm 4.47$ \\
\hline \multirow{5}{*}{ Hematocrit \% } & Screening & $43.35 \pm 2.16$ & $45.71 \pm 9.12$ \\
\cline { 2 - 4 } & Day 1 & $44.13 \pm 3.48$ & $44.41 \pm 1.41$ \\
\cline { 2 - 4 } & Day 2 & $43.97 \pm 2.84$ & $43.32 \pm 2.86$ \\
\cline { 2 - 3 } & Day 3 & $41.88 \pm 3.29$ & $40.22 \pm 3.89$ \\
\cline { 2 - 3 } & Day 5 & $39.26 \pm 3.47$ & \\
\hline
\end{tabular}




\begin{tabular}{|c|c|c|c|}
\hline & Day 7 & $37.0 \pm 3.04$ & $39.27 \pm 3.37$ \\
\hline \multirow{6}{*}{$\begin{array}{ll}\text { Prothrombin } & \text { Time } \\
\text { (seconds) } & \end{array}$} & Screening & $11.21 \pm 1.39$ & $11.10 \pm 1.08$ \\
\hline & Day 1 & $11.14 \pm 1.04$ & $11.27 \pm 1.09$ \\
\hline & Day 2 & $11.42 \pm 1.56$ & $11.38 \pm 1.92$ \\
\hline & Day 3 & $11.86 \pm 1.58$ & $11.91 \pm 1.67$ \\
\hline & Day 5 & $12.05 \pm 0.87$ & $12.09 \pm 0.71$ \\
\hline & Day 7 & $12.0 \pm 1.14$ & $11.90 \pm 0.62$ \\
\hline \multirow[t]{6}{*}{ Clotting Time (minutes) } & Screening & $4.41 \pm 0.74$ & $4.56 \pm 1.37$ \\
\hline & Day 1 & $4.11 \pm 0.56$ & $4.20 \pm 1.06$ \\
\hline & Day 2 & $3.89 \pm 0.99$ & $3.92 \pm 1.49$ \\
\hline & Day 3 & $3.71 \pm 0.84$ & $3.90 \pm 1.67$ \\
\hline & Day 5 & $3.60 \pm 1.07$ & $3.46 \pm 1.15$ \\
\hline & Day 7 & $4.05 \pm 0.67$ & $4.09 \pm 0.47$ \\
\hline \multirow[t]{6}{*}{ Bleeding Time (minutes) } & Screening & $2.10 \pm 1.06$ & $2.20 \pm 1.83$ \\
\hline & Day 1 & $2.14 \pm 0.85$ & $2.23 \pm 0.79$ \\
\hline & Day 2 & $2.10 \pm 1.05$ & $2.24 \pm 1.07$ \\
\hline & Day 3 & $2.16 \pm 0.84$ & $2.40 \pm 1.64$ \\
\hline & Day 5 & $2.18 \pm 1.41$ & $2.39 \pm 0.79$ \\
\hline & Day 7 & $2.16 \pm 1.32$ & $2.40 \pm 1.23$ \\
\hline
\end{tabular}

(Table analysis: Two-way ANOVA followed by Bonferroni post-test. \# $(\mathrm{P}<0.05) \&$ \#\#(P<0.01) - significant)

\section{Fig 7: Improvement in Platelet count}

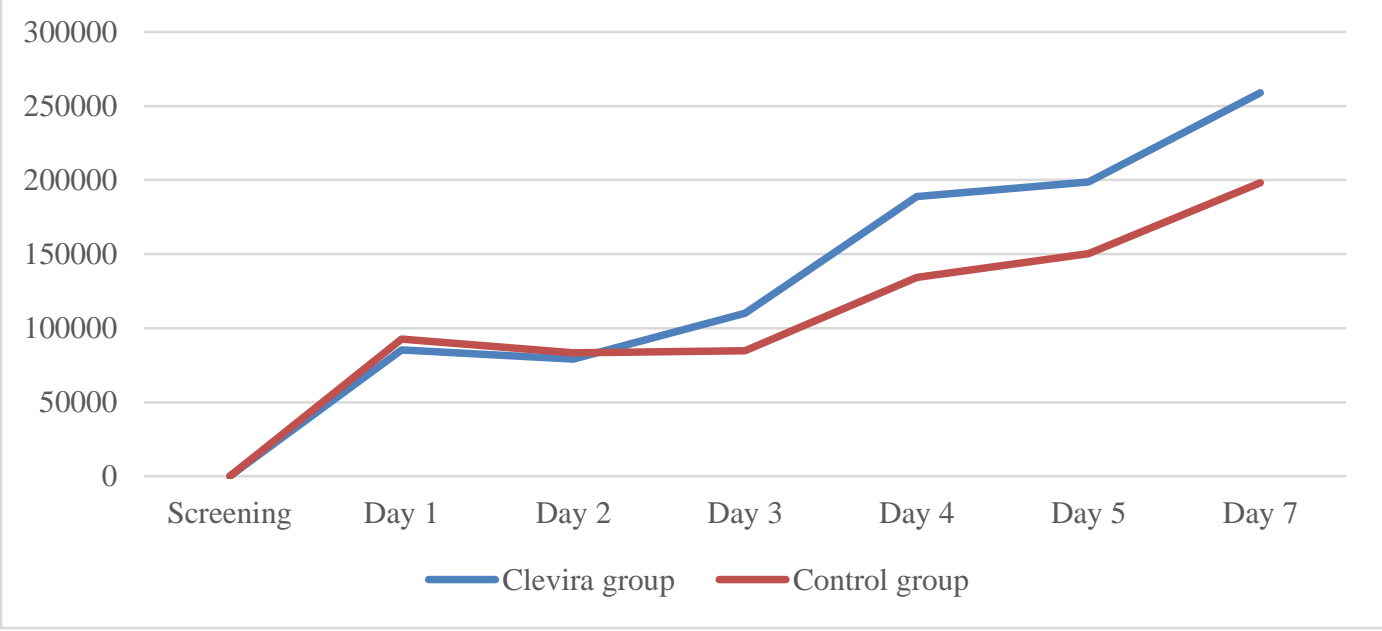

There is significant improvement in the platelet count in both the groups(Table 3). But it was more significant in the Clevira treated group when compared with the control group (Figure 7).

The significant improvement in the platelet count was noted on Day $4(\mathrm{P}<0.05) \#$ and on Day $7(\mathrm{P}<0.01) \# \#$ in the Clevira treated subjects.

There is also a significant improvement in the Haematocrit value in both the groups

Table 4: Assessment of other Haematological parameters

\begin{tabular}{|c|c|c|c|c|c|}
\hline $\begin{array}{l}\text { Haematological Lab } \\
\text { parameters }\end{array}$ & $\begin{array}{l}\text { Scheduled } \\
\text { visits }\end{array}$ & $\begin{array}{l}\text { Group 1(Clevira)- } \\
\text { Viral fever with } \\
\text { thrombocytopenia }\end{array}$ & $\begin{array}{l}\text { Group 2(Control)- } \\
\text { Viral fever with } \\
\text { thrombocytopenia }\end{array}$ & $\begin{array}{l}\text { Group } 3 \text { (Clevira)- } \\
\text { Viral fever without } \\
\text { thrombocytopenia }\end{array}$ & $\begin{array}{l}\text { Group } 4 \text { (Control)- } \\
\text { Viral fever without } \\
\text { thrombocytopenia }\end{array}$ \\
\hline \multirow[t]{2}{*}{ Hemoglobin (\%) } & Screening & $11.3 \pm 1.2$ & $10.92 \pm 0.8$ & $10.7 \pm 0.8$ & $10.7 \pm 0.7$ \\
\hline & Day 7 & $11.1 \pm 0.7$ & $10.76 \pm 0.8$ & $10.9 \pm 0.9$ & $10.9 \pm 0.9$ \\
\hline \multirow{2}{*}{$\begin{array}{l}\text { Total WBC count } \\
\text { cells/mm } / \mathbf{m m}^{3}\end{array}$} & Screening & $10409.1 \pm 1181.9$ & $11533.3 \pm 1047.3$ & $9000 \pm 1041.6$ & $9622.2 \pm 2364.7$ \\
\hline & Day 7 & $8621.6 \pm 2910.2$ & $9541.6 \pm 1439.9$ & $6180 \pm 1932.3$ & $8590.9 \pm 1021.2$ \\
\hline \multirow{2}{*}{$\underset{\# \#}{\text { Neutrophils cells/ } \mathbf{m m}^{3}}$} & Screening & $40.5 \pm 5.2$ & $46.5 \pm 4.1$ & $39.8 \pm 6.2$ & $44.5 \pm 5.4$ \\
\hline & Day 7 & $39.1 \pm 5.4$ & $59.5 \pm 5.6$ & $35.1 \pm 2.6$ & $46.3 \pm 6.4$ \\
\hline \multirow{2}{*}{$\begin{array}{l}\text { Lymphocytes cells/ } \\
\text { mm }^{3 \text { \#\# }}\end{array}$} & Screening & $54.7 \pm 7.3$ & $51.2 \pm 3.9$ & $59.5 \pm 6.1$ & $53.3 \pm 5.1$ \\
\hline & Day 7 & $48.6 \pm 4.7$ & $52 \pm 4.4$ & $32.5 \pm 2.8$ & $51.3 \pm 7.4$ \\
\hline \multirow{2}{*}{ Monocytes cells/ $\mathbf{m m}^{3}$} & Screening & $0.5 \pm 0.6$ & $0.3 \pm 0.4$ & $0.1 \pm 0.3$ & $0.09 \pm 0.3$ \\
\hline & Day 7 & $0.6 \pm 0.9$ & $0.3 \pm 0.4$ & $0.1 \pm 0.3$ & $0.1 \pm 0.3$ \\
\hline \multirow[t]{2}{*}{ Eosinophils cells/ $\mathbf{m m}^{3}$} & Screening & $3.0 \pm 2.2$ & $1.8 \pm 2.1$ & $0.4 \pm 0.5$ & $1.0 \pm 1.0$ \\
\hline & Day 7 & $2.5 \pm 2.0$ & $2.1 \pm 2.1$ & $0.2 \pm 0.5$ & $1.0 \pm 0.8$ \\
\hline \multirow{2}{*}{ Basophils cells $/$ mm $^{3}$} & Screening & $0.4 \pm 0.5$ & $0.5 \pm 0.6$ & $0.6 \pm 0.4$ & $0.5 \pm 0.3$ \\
\hline & Day 7 & $0.4 \pm 0.4$ & $0.3 \pm 0.8$ & $0.5 \pm 0.2$ & $0.4 \pm 0.5$ \\
\hline
\end{tabular}




\begin{tabular}{|l|l|l|l|l|l|}
\hline \multirow{2}{*}{ ESR mm/hr } & Screening & $24 \pm 5.4$ & $28.5 \pm 6.4$ & $30 \pm 8.2$ & $26 \pm 7.6$ \\
\cline { 2 - 6 } & Day 7 & $20 \pm 4.4$ & $24.6 \pm 5.2$ & $26 \pm 9.2$ & $22 \pm 8.5$ \\
\hline \multirow{3}{*}{ SGOT } & Screening & $23.9 \pm 5.2$ & $22.2 \pm 2.9$ & $33.7 \pm 10.2$ & $22.9 \pm 5.2$ \\
\cline { 2 - 6 } & Day 7 & $23.0 \pm 4.2$ & $21 \pm 2.4$ & $20.2 \pm 1.8$ & $21.3 \pm 5.0$ \\
\hline \multirow{3}{*}{ Random Blood sugar } & Screening & $25.8 \pm 5.8$ & $20.7 \pm 2.5$ & $44.1 \pm 12.7$ & $25.8 \pm 6.6$ \\
\cline { 2 - 6 } & Day 7 & $22.6 \pm 3.1$ & $20 \pm 1.4$ & $22.6 \pm 3.7$ & $23.1 \pm 2.4$ \\
\cline { 2 - 6 } & Screening & $120 \pm 20.4$ & $108 \pm 12.1$ & $124 \pm 4.5$ & $100 \pm 18.6$ \\
\cline { 2 - 6 } & Day 7 & $118 \pm 10.5$ & $116 \pm 11.2$ & $130 \pm 10.8$ & $118 \pm 19.5$ \\
\cline { 2 - 6 } & Screening & $23.4 \pm 3.8$ & $20.8 \pm 5.5$ & $20 \pm 4.5$ & $24.1 \pm 2.5$ \\
\hline \multirow{2}{*}{ Serum Creatinine } & Day 7 & $22.8 \pm 4.7$ & $22.6 \pm 3.2$ & $24.4 \pm 3.6$ & $22.8 \pm 6.2$ \\
& Screening & $0.7 \pm 0.09$ & $0.65 \pm 0.1$ & $0.75 \pm 0.1$ & $0.7 \pm 0.1$ \\
\cline { 2 - 6 } & Day 7 & $0.6 \pm 0.08$ & $0.7 \pm 0.1$ & $0.7 \pm 0.1$ & $0.6 \pm 0.1$ \\
\hline
\end{tabular}

(Table analysis: Two-way ANOVA followed by Bonferroni post-test. \#\#(P<0.01) - significant)
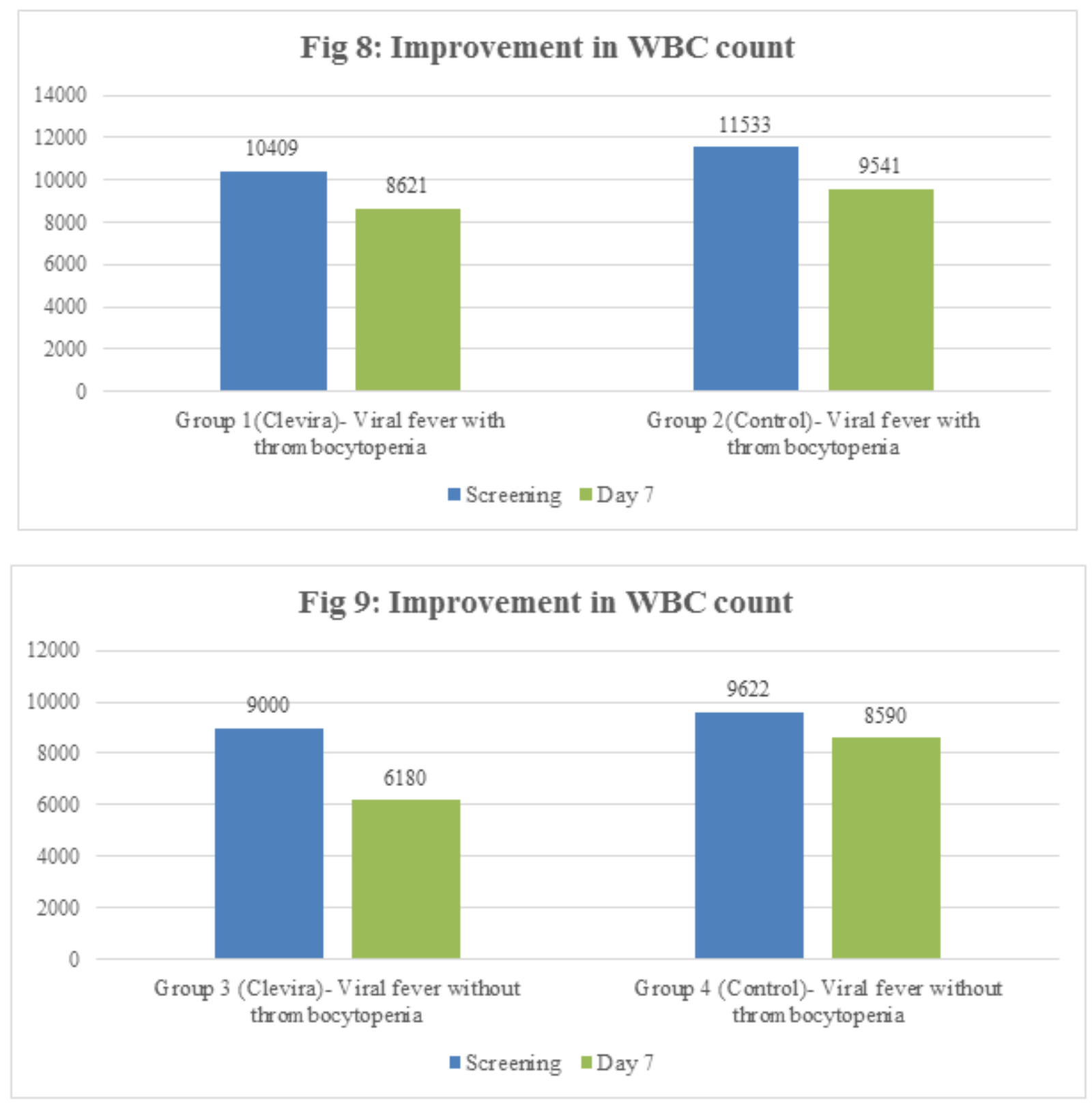

There is significant improvement $(\mathrm{P}<0.01) \# \#$ in the WBC score, Lymphocyte count and Neutrophil count(Table 4) in the Clevira treated group when compared with the control group which is also evident from the Figure $8 \& 9$. This is mainly due to the anti viral property of Clevira. There were no changes noted in the Liver and renal parameters of all the subjects suggesting the safety of Clevira.

Table 5: Questionnaire assessment of Quality of life

\begin{tabular}{|c|c|c|c|c|c|c|c|c|c|}
\hline \multicolumn{2}{|l|}{ Groups } & \multicolumn{2}{|c|}{$\begin{array}{l}\text { Group 1(Clevira) - } \\
\text { Viral fever with } \\
\text { thrombocytopenia. } \\
\mathrm{N}=12\end{array}$} & \multicolumn{2}{|c|}{$\begin{array}{l}\text { Group 2(Control)- } \\
\text { Viral fever with } \\
\text { thrombocytopenia } \\
\mathrm{N}=12\end{array}$} & \multicolumn{2}{|c|}{$\begin{array}{l}\text { Group } 3 \text { (Clevira)- Viral } \\
\text { fever without } \\
\text { thrombocytopenia } N=12\end{array}$} & \multicolumn{2}{|c|}{$\begin{array}{l}\text { Group } 4 \text { (Control)- } \\
\text { Viral fever without } \\
\text { thrombocytopenia } \\
\mathrm{N}=12\end{array}$} \\
\hline $\begin{array}{l}\text { Questionnaire } \\
\text { to assess quality } \\
\text { of Life }\end{array}$ & Scale & Screening & $\begin{array}{l}\text { Post } \\
\text { study }\end{array}$ & Screening & $\begin{array}{l}\text { Post } \\
\text { study }\end{array}$ & Screening & Post study & Screening & $\begin{array}{l}\text { Post } \\
\text { study }\end{array}$ \\
\hline
\end{tabular}




\begin{tabular}{|c|c|c|c|c|c|c|c|c|c|}
\hline \multirow[t]{4}{*}{$\begin{array}{l}\text { Do you feel tired } \\
\text { or fatigued? }\end{array}$} & Always & $\begin{array}{c}10 \\
(83.3 \%)\end{array}$ & 0 & $\begin{array}{c}12 \\
(100 \%)\end{array}$ & 0 & $\begin{array}{c}9 \\
(75 \%)\end{array}$ & 0 & $\begin{array}{c}10 \\
(83.3 \%)\end{array}$ & 0 \\
\hline & Often & $2(16.7 \%)$ & 0 & 0 & 0 & $3(25 \%)$ & 0 & $2(16.7 \%)$ & $2(16.7 \%)$ \\
\hline & Sometime & 0 & $\begin{array}{c}6 \\
(50 \%) \\
\end{array}$ & 0 & $\begin{array}{c}10 \\
(83.3 \%) \\
\end{array}$ & 0 & $\begin{array}{c}4 \\
(33.3 \%) \\
\end{array}$ & 0 & $\begin{array}{c}6 \\
(50 \%) \\
\end{array}$ \\
\hline & Never & 0 & $6(50 \%)$ & 0 & $2(16.7 \%)$ & 0 & $8(66.7 \%)$ & 0 & $4(33.3 \%)$ \\
\hline \multirow[t]{4}{*}{$\begin{array}{l}\text { Do you feel } \\
\text { week? }\end{array}$} & Always & $\begin{array}{c}10 \\
(83.3 \%)\end{array}$ & 0 & $12(100 \%)$ & 0 & $9(75 \%)$ & 0 & $\begin{array}{c}10 \\
(83.3 \%)\end{array}$ & 0 \\
\hline & Often & $2(16.7 \%)$ & 0 & 0 & 0 & $3(25 \%)$ & 0 & $2(16.7 \%)$ & $2(16.7 \%)$ \\
\hline & Sometime & 0 & $6(50 \%)$ & 0 & $12(100 \%)$ & 0 & $4(33.3 \%)$ & 0 & $6(50 \%)$ \\
\hline & Never & 0 & $6(50 \%)$ & 0 & 0 & 0 & $8(66.7 \%)$ & 0 & $4(33.3 \%)$ \\
\hline \multirow{4}{*}{$\begin{array}{l}\text { Do you get short } \\
\text { of breath? }\end{array}$} & Always & 0 & 0 & 0 & 0 & 0 & 0 & 0 & 0 \\
\hline & Often & 0 & 0 & 0 & 0 & 0 & 0 & 0 & 0 \\
\hline & Sometime & $6(50 \%)$ & $\begin{array}{c}2 \\
(16.7 \%) \\
\end{array}$ & $8(66.7 \%)$ & $2(16.7 \%)$ & $8(66.7 \%)$ & 0 & $6(50 \%)$ & $2(16.7 \%)$ \\
\hline & Never & $6(50 \%)$ & $\begin{array}{c}10 \\
(83.3 \%) \\
\end{array}$ & $4(33.3 \%)$ & $\begin{array}{c}10 \\
(83.3 \%) \\
\end{array}$ & $4(33.3 \%)$ & $12(100 \%)$ & $6(50 \%)$ & $\begin{array}{c}10 \\
(83.3 \%) \\
\end{array}$ \\
\hline \multirow{4}{*}{$\begin{array}{l}\text { Do you get } \\
\text { dizzy? }\end{array}$} & Always & 0 & 0 & 0 & 0 & 0 & 0 & 0 & 0 \\
\hline & Often & 0 & 0 & 0 & 0 & $2(16.7 \%)$ & 0 & 0 & 0 \\
\hline & Sometime & $5(41.7 \%)$ & $\begin{array}{c}2 \\
(16.7 \%) \\
\end{array}$ & $8(66.7 \%)$ & $2(16.7 \%)$ & $3(25 \%)$ & 0 & $6(50 \%)$ & $2(16.7 \%)$ \\
\hline & Never & $7(58.3 \%)$ & $\begin{array}{c}10 \\
(83.3 \%) \\
\end{array}$ & $4(33.3 \%)$ & $\begin{array}{c}10 \\
(83.3 \%)\end{array}$ & $7(58.3 \%)$ & $12(100 \%)$ & $6(50 \%)$ & $\begin{array}{c}10 \\
(83.3 \%)\end{array}$ \\
\hline \multirow{4}{*}{$\begin{array}{l}\text { Have you } \\
\text { experienced a } \\
\text { rapid Heart } \\
\text { beat? }\end{array}$} & Always & 0 & 0 & 0 & 0 & 0 & 0 & 0 & 0 \\
\hline & Often & 0 & 0 & 0 & 0 & 0 & 0 & 0 & 0 \\
\hline & Sometime & $\begin{array}{c}10 \\
(83.3 \%) \\
\end{array}$ & 0 & $\begin{array}{c}10 \\
(83.3 \%) \\
\end{array}$ & 0 & $8(66.7 \%)$ & $3(25 \%)$ & $\begin{array}{c}10 \\
(83.3 \%) \\
\end{array}$ & $6(50 \%)$ \\
\hline & Never & $2(16.7 \%)$ & $\begin{array}{c}12 \\
(100 \%) \\
\end{array}$ & $2(16.7 \%)$ & $12(100 \%)$ & $4(33.3 \%)$ & $7(58.3 \%)$ & $2(16.7 \%)$ & $6(50 \%)$ \\
\hline \multirow{4}{*}{$\begin{array}{l}\text { Do you have } \\
\text { numbness or } \\
\text { coldness in your } \\
\text { hands or feets? }\end{array}$} & Always & 0 & 0 & 0 & 0 & 0 & 0 & 0 & 0 \\
\hline & Often & 0 & 0 & 0 & 0 & 0 & 0 & 0 & 0 \\
\hline & Sometime & $5(41.7 \%)$ & 0 & $2(16.7 \%)$ & 0 & $4(33.3 \%)$ & 0 & $4(33.3 \%)$ & $2(16.7 \%)$ \\
\hline & Never & $7(58.3 \%)$ & $\begin{array}{c}12 \\
(100 \%) \\
\end{array}$ & $\begin{array}{c}10 \\
(83.3 \%) \\
\end{array}$ & $12(100 \%)$ & $8(66.7 \%)$ & $12(100 \%)$ & $8(66.7 \%)$ & $\begin{array}{c}10 \\
(83.3 \%) \\
\end{array}$ \\
\hline \multirow{4}{*}{$\begin{array}{l}\text { Are you } \\
\text { irritable? }\end{array}$} & Always & 0 & 0 & 0 & 0 & 0 & 0 & 0 & 0 \\
\hline & Often & 0 & 0 & 0 & 0 & 0 & 0 & 0 & 0 \\
\hline & Sometime & $2(16.7 \%)$ & 0 & $5(41.7 \%)$ & $5(41.7 \%)$ & $4(33.3 \%)$ & 0 & $6(50 \%)$ & $2(16.7 \%)$ \\
\hline & Never & $\begin{array}{c}10 \\
(83.3 \%)\end{array}$ & $\begin{array}{c}12 \\
(100 \%)\end{array}$ & $7(58.3 \%)$ & $7(58.3 \%)$ & $8(66.7 \%)$ & $12(100 \%)$ & $6(50 \%)$ & $\begin{array}{c}10 \\
(83.3 \%)\end{array}$ \\
\hline \multirow{4}{*}{$\begin{array}{l}\text { Do you feel sad } \\
\text { or depressed? }\end{array}$} & Always & 0 & 0 & 0 & 0 & 0 & 0 & 0 & 0 \\
\hline & Often & $3(25 \%)$ & 0 & $6(50 \%)$ & 0 & 0 & 0 & 0 & 0 \\
\hline & Sometime & $3(25 \%)$ & $\begin{array}{c}5 \\
(41.7 \%) \\
\end{array}$ & $6(50 \%)$ & $6(50 \%)$ & $8(66.7 \%)$ & $2(16.7 \%)$ & $6(50 \%)$ & $4(33.3 \%)$ \\
\hline & Never & $6(50 \%)$ & $\begin{array}{c}7 \\
(58.3 \%)\end{array}$ & 0 & $6(50 \%)$ & $4(33.3 \%)$ & $10(83.3 \%)$ & $6(50 \%)$ & $8(66.7 \%)$ \\
\hline
\end{tabular}

The Quality of life was assessed in percentage based on the subjects response. The results shows that the quality of life (percentage scored) was better in Clevira treated group compared with the control group at the end of the study.

Table 6: Adverse events observed during the study period.

\begin{tabular}{|l|l|l|l|l|}
\hline & $\begin{array}{l}\text { Group 1(Clevira)- Viral fever } \\
\text { with thrombocytopenia } \\
\text { (No. of subjects) }\end{array}$ & $\begin{array}{l}\text { Group 2 (Control)- } \\
\text { Viral fever with } \\
\text { thrombocytopenia } \\
\text { (No. of subjects) }\end{array}$ & $\begin{array}{l}\text { Group 3 (Clevira)- } \\
\text { Viral fever without } \\
\text { thrombocytopenia } \\
\text { (No. of subjects) }\end{array}$ & $\begin{array}{l}\text { Group 4 (Control) - } \\
\text { Viral fever without } \\
\text { thrombocytopenia } \\
\text { (No. of subjects) }\end{array}$ \\
\hline Nausea & 3 & 5 & 4 & 2 \\
\hline Vomiting & 2 & 3 & 5 & 4 \\
\hline Diarrhoea & 2 & 2 & 1 & 0 \\
\hline Gastritis & 4 & 3 & 3 & 2 \\
\hline Giddiness & 2 & 2 & 3 & 2 \\
\hline Allergic reactions & 0 & 0 & 0 & 0 \\
\hline
\end{tabular}

There were no serious adverse events observed during the study period.

Table 7: Overall assessment of the study outcome by the Investigator:

\begin{tabular}{|l|l|l|l|l|}
\hline $\begin{array}{l}\text { Overall impression by } \\
\text { the Investigator }\end{array}$ & $\begin{array}{l}\text { Group 1(Clevira) }- \\
\text { Viral fever with } \\
\text { thrombocytopenia } \\
\text { (No. of Subjects) }\end{array}$ & $\begin{array}{l}\text { Group 2 (Control) - } \\
\text { Viral fever with } \\
\text { thrombocytopenia } \\
\text { (No. of Subjects) }\end{array}$ & $\begin{array}{l}\text { Group 3 (Clevira) - } \\
\text { Viral fever without } \\
\text { thrombocytopenia } \\
\text { (No. of Subjects) }\end{array}$ & $\begin{array}{l}\text { Group 4 (Control) - } \\
\text { Viral fever without } \\
\text { thrombocytopenia } \\
\text { (No. of Subjects) }\end{array}$ \\
\hline CURED & $11(4 *)$ & 10 & 10 & 7 \\
\hline
\end{tabular}




\begin{tabular}{|l|l|l|l|l|}
\hline Marked improvement & $1\left(1^{*}\right)$ & 1 & 1 & 2 \\
\hline Moderate improvement & 0 & $3\left(2^{*}\right)$ & 1 & 1 \\
\hline Slight improvement & 0 & 0 & 0 & 2 \\
\hline
\end{tabular}

*There were nine confirmed cases of Dengue NS1 positive, out of which five were in the Clevira group and four were in the control group.

\section{Fig 10: Overall Cure Rate}

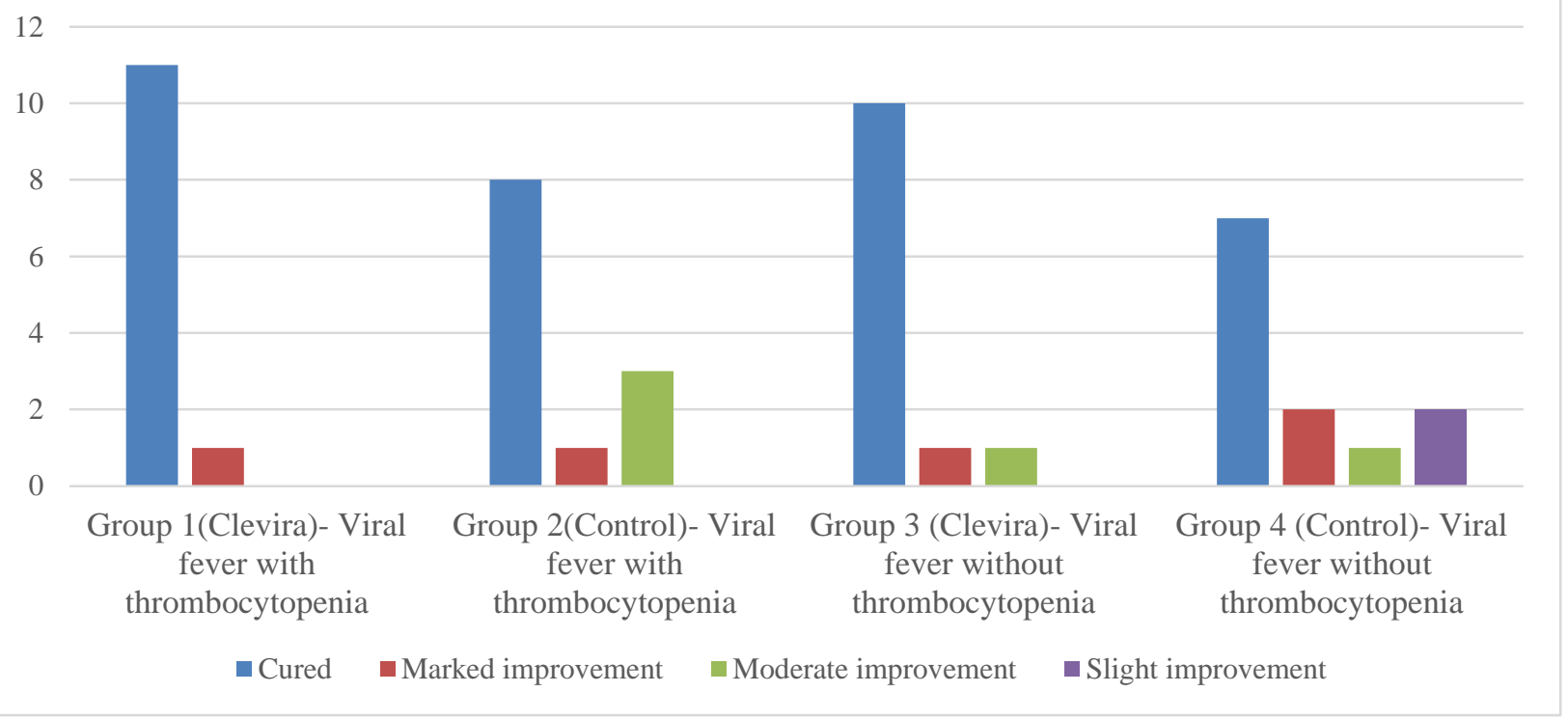

\section{Discussion}

In this study, there was a significant reduction in the mean score of all the clinical symptoms in both the groups, which was more prominent in Clevira group. The platelet count was significantly normalized in Clevira treated subjects earlier by 3rd and 4th day when compared to the control group, were it was normalized on day 5 and above (figure 7). Thus, Clevira has overturned thrombocytopenia and led to platelet level regulation.

From the study results, it is clear that the normalisation of body temperature was evident on Day 5 onwards in Clevira treated group, compared to the control group were it was normalised after day 6 and 7. Thus, Clevira is having a good anti Pyretic activity. It is also evident that Clevira is having a significant improvement $(\mathrm{P}<0.001)^{*}$ in the Arthralgia and Myalgia score on day 3, 4 \& 5, compared to the control group were it was improving on day 5, 6 and 7, suggesting a good Analgesic and anti pyretic activity of Clevira.

All the haematological and biochemical parameters were within the normal range with significant reduction in haematocrit and WBC count, suggesting the anti-Viral property and immunomodulatory capacity of Clevira against Dengue infections and other viral infectious fever conditions. Unaltered Renal and liver function tests suggests the Safety of Clevira tablets at the recommended dose.

There was a significant improvement in the quality of life of subjects in Clevira group related to the fatigue, sense of feeling week, dizziness and sense of feeling depressed, compared to that of baseline and control group. The overall response (figure 10) of the Clevira group showed $80 \%$ of the total subjects were completely free from dengue signs and symptom compared to $50 \%$ in the control group and a very good subject compliance was observed. There were no clinically significant adverse event during the entire study period.

Clevira, the ayurvedic preparation made of herbs like Carica papaya, Melia azedarach, Andrographis paniculata, Vettivera zizanoides, Tricosanthus dioica, Cyperus rotundus, Zingiber officinale, Piper nigrum, Mollugo cerviana, Tinospora cordifolia. Carica papaya is known for its anti-dengue and platelet augmentation activity. It is reported to be having enhancement of arachidonate 12-lipoxygenase and the platelet activating factor receptor gene expression which is responsible for increased platelet production. It also decreases peripheral platelet destruction by membrane stabilizing activity due to presence of many flavonoids and phenolic compounds, which could have facilitated the significant increase in platelet counts in Clevira treated patients. . $^{[7,10,12]}$

Andrographis paniculata is a medicinal plant which was reported to have anti HIV, anti pathogenic bacteria and immunoregulatory activities which also possess blood purifying activity and thus eliminates the toxic metabolites and have antiinflammatory, anti-pyretic and analgesic activity. ${ }^{[11,13]}$ Limonoids from Melia azedarach Fruits has been shown to have inhibitory activity on Flaviviruses and Mycobacterium tuberculosis. ${ }^{[14,15]}$

Tinospora cordifolia which is known to strengthen host immune system by activating macrophages, NF-kappa beta translocation and cytokine production in addition its anti-pyretic, antiviral and hepato-protective activity. ${ }^{[16]}$ Piper nigrum has shown to increase the bioavailability of drugs, protects the liver and neutralizes the endotoxins and detoxifies pathogenic remnants from liver and blood. Possess analgesic, anti-inflammatory, antibacterial, antifungal activities. Possesses immunomodulatory effect which prevent the disease occurrence could have potentially facilitated the significant reduction in clinical signs and symptoms of dengue fever associated with thrombocytopenia and in case of other viral fever patients. ${ }^{[17]}$

Zingeber officinale is also reported to possess antipyretic, analgesic, anti-arthritic, and anti-inflammatory activities. It stimulates the secretion of gastric enzyme to recover appetite and digestion. ${ }^{[18]}$ Cyperus rotandus possess anti-inflammatory, antipyretic and anti-arthritic properties. Controls systemic inflammations and reduce fever. It also has anti-oxidant effect. ${ }^{[19]}$ 
Thus, the Poly herbal preparation of Clevira can reverse the low platelet counts due to dengue viral fever(anti-dengue) and other clinical conditions, which are associated with mild to moderate thrombocytopenia and thus hastens the recovery. From the discussion, it is also clear that Clevira has anti-viral, antiinflammatory, anti-pyretic, anti-arthritic, immunomodulatory and anti-oxidant properties.

\section{Conclusion}

In conclusion, from the results and discussions of the present study, Clevira is safe and efficacious in reversing thrombocytopenia and thus normalizing the platelet counts and relieving the clinical signs and symptoms (fever, myalgia, arthralgia, headache) of Viral fever associated with thrombocytopenia and other cases of viral fever without thrombocytopenia when compared to that of the control group. Thus, Clevira (polyherbal combination) is having good antiviral, antipyretic, analgesic, anti-arthritic and immunomodulatory property.

Henceforth, Clevira can be used as an add on drug in patients with viral fever with or without thrombocytopenia to relieve the signs and symptoms of it and for a rapid recovery without any adverse effects.

\section{Source(s) of support}

Nil

\section{Conflicting Interest}

Nil

\section{Conflict of Interest}

All authors have none to declare.

\section{Acknowledgement}

We acknowledge the CRO-Ki3 \& Sponsor-Apex Laboratories Pvt. Ltd., for supporting us right throughout this study.

\section{References}

1. Colvin JM, Muenzer JT, Jaffe DM, Smason A, Deych E, Shannon WD, Arens MQ, Buller RS, Lee WM, Weinstock EJ, Weinstock GM, Storch GA. Detection of viruses in young children with fever without an apparent source. Pediatrics. 2012 Dec;130(6):e1455-62.

2. González Plaza JJ, Hulak N, Zhumadilov Z, Akilzhanova A. Fever as an important resource for infectious diseases research. Intractable Rare Dis Res. 2016 May;5(2):97102.

3. Pinheiro FP, Corber SJ. Global situation of dengue and dengue haemorrhagic fever and its emergence in the Americas. World Health Stat Q 1997;50:161-8.

4. World Health Organisation. Prevention and control of dengue and dengue haemorrhagic fever: comprehensive guidelines. WHO Regional publication, SEARO, No 29, 1999.

5. Brady OJ, Gething PW, Bhatt S, Messina JP, Brownstein JS, Hoen AG et al. Refining the global spatial limits of dengue virus transmission by evidence-based consensus. PLoS Negl Trop Dis. 2012;6:e1760.

6. Bhatt S, Gething PW, Brady OJ, Messina JP, Farlow AW, Moyes CL et.al. The global distribution and burden of dengue. Nature;496:504-507.

7. Sarala N, Paknikar. Papaya extract to treat dengue: A novel therapeutic option? Annals of Medical and Health Sciences Research 2014;4:32-24.

8. Dengue- Disease management and investigative guidelines, Kansan Department of health and environment, division of health 2015.

9. Xu M, Zuest R, Velumani S, Tukijan F, Toh YX, Appanna $\mathrm{R}$, et al. A potent neutralizing antibody with therapeutic potential against all four serotypes of dengue virus. NPJ Vaccines. 2017;2:2.

10. Kasture PN, Nagabhushan KH, Kumar. A Multi-centric, Double-blind, Placebo-controlled, Randomized, Prospective Study to Evaluate the Efficacy and Safety of Carica papaya Leaf Extract, as Empirical Therapy for Thrombocytopenia associated with Dengue Fever. J Assoc Physicians India. 2016;64(6):15-20.

11. Churiyah, Pongtuluran OB, Rofaani E, Tarwadi. Antiviral and Immunostimulant activities of Andrographis paniculata. HAYATI Journal of Biosciences April 2015;22(2):67-72.

12. Srikrishna $\mathrm{H} \mathrm{A}$, et al. Clinical Evaluation for the Thrombopoietic Activity of Platenza Tablet in Cases of Dengue with Thrombocytopenia - Randomized Open Label Comparative Clinical Study. Ann Med Health Sci Res. 2018; 8: 29-38.

13. Kuadkitkan A, Wikan N, Ubol S, Roytrakul S, Chu JJ, Smith DR. Activity of andrographolide against chikungunya virus infection. Scientific Reports 5:2015 pg 14179.

14. Sanna G, Madeddu S, Giliberti G, Ntalli NG, Cottiglia F, De Logu A, et al. (2015) Limonoids from Melia azedarach Fruits as Inhibitors of Flaviviruses and Mycobacterium tubercolosis.PLoS ONE 10(10): e0141272.

15. Alche LE, Ferek GA, Meo M, Coto CE, Maier MS. An antiviral meliacarpin from leaves of Melia azedarach L. Naturforsch C. 2003 Mar-Apr;58(3-4):215-9.

16. Kavitha BT, Shruthi SD, Rai SP, Ramachandra YL. Phytochemical analysis and hepatoprotective properties of Tinospora cordifolia against carbon tetrachlorideinduced hepatic damage in rats. Journal of Basic and Clinical Pharmacy. 2011;2:139.

17. Wadhwa S, Singhal S, Rawal S. Bioavailability enhancement by piperine: A review. Asian Journal of Biomedical and Pharmaceutical Sciences. 2014;4:1.

18. Rahnama P, Montazeri A, Huseini HF, Kianbakht S, Naseri M. Effect of Zingiber officinale R. rhizomes (ginger) on pain relief in primary dysmenorrhea: a placebo randomized trial. BMC Complement Altern Med. 2012 Jul 10;12:92.

19. Al-Snafi AE. A review on Cyperus rotundus A potential medicinal plant. IOSR Journal of Pharmacy. Volume 6, Issue 7 Version. 2 (July 2016), PP. 32-48. 